\title{
Applying critical discourse analysis in the translation of Maghrebian literature
}

Hassan Ou-hssata

English Department, Sultan Moulay Slimane University, Morocco

https://doi.org/10.36505/ExLing-2018/09/0021/000354

\begin{abstract}
Within the frames of Descriptive Translation Studies (DTS) and Critical Discourse Analysis (CDA), this paper examines the several factors that exert influence upon translating texts both as a process and a product. More precisely, it investigates the notion of ideology with particular use of critical discourse analysis. The purpose is to see the degree to which the translator's socio-cultural and ideological backgrounds have impacts on translations. It also aims to shed light on the potential relationship between language (as a discourse) and ideology in translated texts. This work is a mixed research method study whose corpus is a combination of two literary Maghribi texts along with their translated counterparts. Through a two-level analysis (the macro-level and the micro-level), data analysis aims to find out the dissimilarity between the proportions of the information obtained from the target texts (TTs) and their equivalent at the source text (STs). The results obtained in this research proved that the application of CDA of the STs and TTs helps becoming aware of the genre conventions, social and situational context of the ST and TT, and outlines the formation of power and ideological relations on the text-linguistic level.

Key words: Critical discourse analysis, ideology, translation
\end{abstract}

\section{Introduction}

This paper is based on the integration of Critical Discourse Analysis (CDA) in Translation Studies (TS). CDA has become an independent field within linguistics and it is continuously adapted to new phenomena, one of them being TS. The existing research in the respective field consists of a cluster of different approaches and does not provide an applicable framework that may be used as an auxiliary tool in the translation process for the analysis of source texts (ST) and target texts (TT). Thus, the main aim of this thesis is to create a set of CDA guidelines, combining the CDA framework by Norman Fairclough (1989) with the existing approaches of CDA within TS created by Basil Hatim and Ian Mason (1990; 1997) and Christina Schäffner (1997; 2002; 2003 ; 2004), as well as to prove that CDA may be a useful tool in the determination of the social and situational context, power relations and ideological struggle during the translation process of political texts.

ExLing 2018: Proceedings of 9th Tutorial and Research Workshop on Experimental Linguistics, 28-30 August, Paris, Frannce 


\section{Translation-oriented source text analysis}

The application of CDA in TS is usually performed in two ways: a) the framework may be applied to the analysis of the ST and b) the framework may be applied to the analysis of the TT.

In both cases the aim of the approach remains the same, i.e. to determine what ideological or power relations are reflected in lexical, grammatical and structural elements of the text, how they contribute to the overall rhetorical purpose of the text as well as whether the respective information can be useful to the translator during the translation process. Because of the conference constraints, the focus -as a first leg- is on the analysis of the ST.

\section{Social context}

The rule of thumb when CDA is applied for the analysis of texts is the to determine the social and situational contexts within which communication takes place and which determine the roles of the participants. There is no doubt that in order to produce a successful translation, translators must be able to get the intended meaning of the ST producer. Hatim and Mason (1990:224) describe translators as "privilege readers" of the ST, because the translator reads in order to produce and decodes in order to re-encode.

For a translator to be able to interpret the situational and social context within which the communicative event takes place, it is necessary to have at least basic understanding of the topics in the ST. Without the necessary background knowledge, the translator would not be able to uncover the underlying motivations behind the choice of linguistic or grammatical elements and their contribution to the creation of unequal power relationships, if any, between the participants of the communicative event.

The Maghreb literature of French language is a literary production, born under the French colonial period, in the three countries of the Maghreb: Morocco, Algeria and Tunisia. This literature was born mainly around the years 1945-1950 in the Arab Maghreb countries. The authors of this literature are indigenous, that is native to the country. Maghreb literature will become a recognized form of expression after the Second World War. This literature attracts the sympathy of the French-speaking peoples to make them adhere to their cause: To obtain independence and later to resist power structures left after independence.

This information immediately signals a clash between two world views - the Western societies and Third World countries in Northern Africa. 


\section{Situational context}

The social context determines the situational context, i.e. the relationship between participants, power and distance aspects and language use in the communicative event. The translator must be aware of the type of genre and what constraints the respective genre imposes on the texture and structure of the text in both the ST and the TT. The source texts are considered to be political due to following factors: the characters and interlocutors represent opposite social groupings of the global society;

In 'Praise of Defeat', there are two characters " $\mathrm{A}$ " and "B", both of them forming the same narrator. This can be seen as a medium of two contradictory speeches. The issues raised in the source texts concern framing two distinct yet complementary approaches to Moroccan modern literature, culture and politics.

Indeed, while Abdellatif Laâbi was committed to overt political activism in the Moroccan Left during the Years of Lead, Khatibi embodied the figure of a prolific postcolonial thinker.

the writers are themselves politicians and are interested in politics.

In brief, with regards to the types of power exercised through the choice of textual elements in the source texts, the translators' tasks are to reproduce the unequal power relations by spotting the respective power relations in the ST and then choosing the correct linguistic elements in the TL which would thus create an equivalent effect in the TL.

\section{Text-linguistic analysis of source text}

According to CDA, the choice of textual elements reflects the text producer's intentions and linguistic, social and political background. Translators must be aware of the fact that the social and situational context determines the vocabulary, syntax and the overall organization of the text of the political discourse in particular.

\section{Vocabulary and Grammatical Structures}

Ideological struggle and power relations may be exercised implicitly through lexis and grammatical structures. The CDA research within TS has been mainly based on the analysis of lexical and grammatical structures and their role in the translation process. Intertextuality and interdiscursivity are closely connected with the analysis of lexis, because language users recognize the meaning on the basis of their background knowledge and experience dealing with other texts and discourses. Thus, the translator must be able to detect the underlying ideological patterns and possible positive or negative connotations of lexical elements in the 
$\mathrm{ST}$ in order to establish equivalence between the ST and the TT by choosing appropriate textual elements on word level as well.

In his foreword to the translation of Laâbi's volume of selected poetry, Pierre Joris aptly notes that the Moroccan poet "writes with a quiet, unassuming elegance that holds and hides the violence any act of creation proposes" (p.iii). This contrast between quietness and violence, elegance and resistance, love and revolt, is one of the most central features of Laâbi's poetry. 'Praise of Defeat' offers an impressive view of how this contrast has evolved throughout Laâbi's career. Starting with his early poems from the period of Souffles, marked by a disrupted and disorientating syntax, the poet is already aware of the social and political impact of his creation as he writes: "now I know what power inhabits me peoples run through my language" (p.5). A space of collective subversion, awakening and renewal, poetry serves the revolutionary project of "building a kingdom / of insubordination" (p.11).

\section{Conclusion}

The ideological struggle in the texts is between two world views:. The writers explicitly and inexplicitly represent and defend the opinion expressed by the Maghrebian culture. This position and the genre of the text allow them to acquire an implicit position of resistance and revolt against any type of power abuse, so that they become what Fairclough (1989) defines as a "gatekeeper" of a cross-cultural encounter. The gatekeeper phenomenon results in the fact that the writers belong to the submissive yet resistant culture of the Maghrebian society.

\section{References}

Chilton, P.A., Schäffner, C. 2002 Amsterdam: John Benjamins Publishers.

Fairclough, N. 1989. Language and Power. London: Longman.

Fairclough, N. 1999. Critical Discourse Analysis: The Critical Study of Language. London: Longman.

Hatim, B. Mason, I. 1997. The Translator as Communicator. London and New York: Routledge.

Hatim, B., Mason, I. 1990. The Discourse and the Translator. London: Longman.

Schäffner, C. 2002. The Role of Discourse Analysis for Translation and in Translation Training. Clevedon: Multilingual Matters.

Schäffner, C. 1997. Strategies of translating political texts. In Trosborg, A. (Ed.), Text typology and translation, 19-143. Amsterdam: John Benjamins.

Schäffner, C. 2003. Third Ways and new centres - ideological unity or difference? In Calzada-Pérez, M. (Ed.), Apropos of ideology: Translation studies on ideology ideologies in translation studies, 23-41. Manchester: St Jerome Publishing. 